\title{
Port-access minimally invasive surgery for atrial septal defects: A 10-year single-center experience in 166 patients
}

\author{
Nicola Vistarini, MD, ${ }^{\mathrm{a}}$ Marco Aiello, MD, ${ }^{\mathrm{a}}$ Gabriella Mattiucci, MD, ${ }^{\mathrm{a}}$ Alessia Alloni, MD, ${ }^{\mathrm{a}}$ \\ Barbara Cattadori, MD, ${ }^{\mathrm{a}}$ Carmine Tinelli, MD, ${ }^{\mathrm{b}}$ Carlo Pellegrini, MD, ${ }^{\mathrm{a}}$ Andrea Maria D'Armini, MD, ${ }^{\mathrm{a}}$ and \\ Mario Viganò, $\mathrm{MD}^{\mathrm{a}}$
}

Objective: We assessed the surgical results and the benefits to the patient of a minimally invasive surgical approach for atrial septal defects.

Methods: Between May 1998 and May 2008, 166 patients (median age, 44 years) had surgery for atrial septal
defects in our institution. Of these patients, $118(71 \%)$ had a patent foramen ovale (associated with atrial septal
aneurysm in 48 cases), $33(20 \%)$ had a wide ostium secundum defect, $6(3.6 \%)$ had an ostium primum defect, 6
$(3.6 \%)$ had a sinus venosus defect with abnormal pulmonary vein connection, and $1(0.6 \%)$ had a coronary sinus
defect. In 2 cases $(1.2 \%)$ patients were referred to our department for surgical correction after failure of interven-
tional occluder placement. All patients were operated on via a right minithoracotomy (mean incision, $5.5 \pm 1 \mathrm{~cm})$
in the fourth intercostal space and under cardiopulmonary bypass.

Results: The HeartPort access system was used in 106 patients (64\%), with an endoaortic clamp (central kit in 50 cases and peripheral kit in 56). In the remaining patients (36\%), we preferred the Portaclamp system (37 cases) or the Chitwood clamp (23 cases). Average crossclamp time was $38.4 \pm 22.2$ minutes with a mean cardiopulmonary bypass time of $64.9 \pm 34.5$ minutes. There was no conversion in classic sternotomy. There were no early or late hospital deaths. Surgical revision was performed in 6 patients for bleeding from the thoracic wall. The mean hospital stay was 5.8 days. At 51 months mean follow-up, 4 patients died of non-cardiac-related causes.

Conclusions: Port-access minimally invasive surgery for atrial septal defects is a safe, less-invasive, reproducible, and cosmetic operation, providing an excellent outcome and an effective correction, and could be now considered the standard approach for this type of patient.(J Thorac Cardiovasc Surg 2010;139:139-45)

\section{Earn CME credits at}

http://cme.ctsnetjournals.org

Surgical repair of atrial septal defects (ASDs) has been performed for more than 50 years and has been considered superior, compared with medical therapy, in terms of longterm survival and prevention of functional deterioration. ${ }^{1}$ Contemporaneously, since 1976, transcatheter closure of ASDs has gradually become an effective alternative to surgical treatment. ${ }^{2,3}$ This procedure avoids operative trauma and surgical wounds and reduces hospital stay, although it is associated with occasional major complications. ${ }^{4}$ In this scenario, the conventional surgical approach was no longer competitive. Therefore, full sternotomy has been gradually

\footnotetext{
From the Cardiac Surgery Department ${ }^{\mathrm{a}}$ and Clinical Epidemiology and Biometric Unit, ${ }^{\mathrm{b}}$ Fondazione IRCCS Policlinico San Matteo, Pavia, Italy.

Received for publication Jan 17, 2009; revisions received May 26, 2009; accepted for publication July 5, 2009; available ahead of print Aug 26, 2009.

Address for reprints: Nicola Vistarini, MD, Divisione di Cardiochirurgia, Reparti Speciali, Fondazione IRCCS Policlinico San Matteo, Viale Golgi 19, 27100, Pavia, Italy (E-mail: nvistar@tin.it).

0022-5223/\$36.00

Copyright (C) 2010 by The American Association for Thoracic Surgery doi:10.1016/j.jtcvs.2009.07.022
}

replaced by different minimally invasive techniques that guarantee a safe surgical act, shorter hospital stay, good cosmesis, and a durable correction. ${ }^{5-8}$

During the period from May 1998 and May 2008, "portaccess" surgery, via a right minithoracotomy, became the standard approach for ASDs at our institution. The aim of this study is to assess surgical results, long-term outcomes, and benefits to the patient of a minimally invasive approach for ASDs.

\section{MATERIALS AND METHODS Patients}

From May 1998 to May 2008, 166 patients had surgical repair of ASDs at our center, and they constitute the subjects of this study. This retrospective study was performed in accordance with the ethical standards of our ethics committee and adheres to all legal requirements of our institution. There were 116 women $(70 \%)$ and 50 men $(30 \%)$, with a median age of 44 years (range, 4-82). Of these patients, $118(71 \%)$ had a patent foramen ovale (associated with atrial septal aneurysm in 48 cases $), 33(20 \%)$ had a wide ostium secundum defect, $6(3.6 \%)$ had an ostium primum defect (associated with mitral valve cleft in 3 cases), 6 (3.6\%) had a sinus venosus defect with partial abnormal pulmonary vein connection, and $1(0.6 \%)$ had a coronary sinus defect. In 2 cases $(1.2 \%)$, patients were referred to our department for surgical correction after failure of interventional occluder placement: in 1 patient, it was an Amplatzer septal occluder (AGA Medical Corporation, Golden Valley, Minn), and in the other, a Cardia Starr device occluder (Cardia Inc, Burnsville, Minn). Seventy-nine patients (47.6\%) were in New York Heart Association (NYHA) functional class I, 51 (30.7\%) were in class II, 


\author{
Abbreviations and Acronyms \\ ASD $=$ atrial septal defects \\ $\mathrm{CPB}=$ cardiopulmonary bypass \\ NYHA $=$ New York Heart Association \\ PTFE $=$ polytetrafluoroethylene
}

and $36(21.7 \%)$ were in class III. The most common clue to the presence of an ASD was a neurologic symptom ( $47 \%$ of patients), represented by a transient ischemic attack (61 cases) or the presence of recurring migraine (17 cases). All patients were evaluated by transthoracic or transesophageal echocardiography preoperatively. Right heart catheterization was necessary in only 22 patients, and the pulmonary-to-systemic blood flow ratio was determined by oximetry. Coronary angiography was performed in patients over 35 years of age, but no significant coronary artery disease was found. Peripheral vascular disease of the iliac or femoral vessels was not an exclusion criterion for the port-access approach because, in these cases, a central cannulation of the aorta could be always performed. Other preoperative data of the population are presented in Table 1 .

\section{Anesthesia}

Double-lumen intubation for single-lung ventilation was used routinely. There are several reasons why we chose this: (1) high percentage of central arterial cannulation (53\% of cases in our ASD series); (2) less risk of injuries to the right lung during the dissection phase and easier preparation of the patient; (3) no need for cardiopulmonary bypass (CPB) in case of adherences; (4) minimization of the time of deflation of both lungs (before and after CPB); (5) easier control of possible bleedings (from the heart or the thoracic wall) at the end of CPB. Both radial arteries were cannulated when invasive monitoring of the endoaortic clamp was necessary. A 4F catheter was systematically positioned into the right jugular vein by the anesthesiologist, and it was later substituted by the surgeon with a DLP arterial cannula (Medtronic, Inc, Minneapolis, Minn) for selective venous drainage. Transesophageal echocardiography was performed in all patients to confirm and specify the diagnosis, to control the intravascular placement of portaccess cannulas, to facilitate the deairing process, and to evaluate the result of septal closure.

\section{Procedures}

The port-access approach is a minimally invasive technique that allows surgery via a small thoracotomy. The patient is placed in the supine position, with the right side of the chest elevated to improve the exposure and facilitate the operation. A 4- to 6-cm right subthoracic incision is made (Figure 1, A) and the fourth intercostal space is opened. After deflation of the right lung, first a "soft tissue" retractor (CardioVations of Edwards Lifesciences, Inc, Irvine, Calif) is inserted into the thoracotomy (Figure 1, $B$ ), and then a Heartport rib retractor (CardioVations of Edwards Lifesciences) is placed (Figure 1,C); an excellent exposure of the operative field is usually obtained with this procedure (Figure 1,D). A pericardiotomy is made $3 \mathrm{~cm}$ anterior to the phrenic nerve, and pericardial stay sutures are placed and passed out of the chest. All patients are operated under CPB. The venous drainage is obtained by cannulating both femoral $(22 \mathrm{~F}$ or $25 \mathrm{~F}$ CardioVations long venous cannula) and jugular vein (14F or 17F DLP arterial cannula), and the arterial cannulation is obtained by using the femoral artery (peripheral kit) or the ascending aorta (central kit). When a peripheral kit is used, the right femoral vessels are exposed through a transverse 3 -cm incision in the femoral crease, and both vein and artery (using a $21 \mathrm{~F}$ or $23 \mathrm{~F}$ CardioVations arterial cannula) are cannulated through a purse-string suture and under direct vision. When a central kit is used, the femoral vein is cannulated percutaneously, and the ascending aorta is cannulated under direct vision with a central percutaneous 23F "DirectFlow" cannula (CardioVations of Edwards Lifesciences), passed in a trocar through the first intercostal space, inserted into the aorta with the "AutoIncisor" device (CardioVations of Edwards Lifesciences, Inc; Figure 2), and fixed with a double purse-string suture. The aortic clamping could be obtained with an "EndoClamp" (central or peripheral endoaortic balloon) or transthoracically with the Chitwood clamp (Scanlan International, St. Paul, Minn) or the Portaclamp system (Cardio Life Research SA, Louvain la Neuve, Belgium). Both caval veins are encircled by vascular loops and snared to install total CPB. After endoaortic or transthoracic clamping, the heart is arrested with anterograde cold cardioplegia (delivered through a DLP cannula or directly from the extremity of the balloon, in case of endoaortic clamp), and the right atrium is opened longitudinally. Stay sutures are placed to expose the atrial cavity and the ASD is examined; depending on the size of the defect, the closure of the ASD and/or the resection or plication of the interatrial aneurysm is performed either with a simple direct closure, using single stitches of Ethibond 3-0 (Ethicon, Inc, Somerville, NJ) with Teflon pledgets, tied outside the atrium into the interatrial groove, or with a polytetrafluoroethylene (PTFE) patch (W. L. Gore \& Associates, Inc., Flagstaff, Ariz). The mitral valve clefts are repaired by using interrupted 5-0 Prolene sutures (Ethicon). The partial anomalous pulmonary venous connections are corrected by creating a PTFE patch tunnel redirecting the pulmonary venous blood return into the left atrium. The ventricular septal defect is closed with a series of Ethibond 3-0 mattress sutures (Ethicon), supported by small PTFE pledgets. The mitral valve is repaired using standard repair techniques, and for the tricuspid valve, a De-Vega valvuloplasty is performed. Surgical ablation therapy for chronic atrial fibrillation has been made with a right-sided maze procedure with radiofrequency. The procedure is always carried out under mild systemic hypothermia (mean esophageal temperature: $33^{\circ} \mathrm{C}$ ). After completion of the operation, the atriotomy is closed with a 4-0 Prolene suture (Ethicon), and decannulation is carried out. Afterward, a $24 \mathrm{~F}$ to $28 \mathrm{~F}$ curved chest tube is inserted into the right pleura, a Jackson-Pratt is placed over the right atrium, and the pericardium is closed above it, with separate stitches. After an adequate hemostasis, the chest and the wounds are closed cosmetically.

\section{Statistical Analysis}

Descriptive data for continuous variables are presented as means with standard deviation. Logistic regression models were used for univariate analysis, and results are presented as odds ratios with their $95 \%$ confidence intervals. Analysis was performed with STATA software (StataCorp, 2006, Stata Statistical Software: release 9.0, College Station, Tex).

\section{RESULTS \\ ASD Surgery}

Surgery was always performed in elective conditions, and no conversions to median sternotomy were needed. The arterial cannulation was obtained by using the femoral artery in 78 patients $(47 \%)$ and the ascending aorta in 88 patients $(53 \%)$, and the venous drainage was always obtained by cannulating both femoral and jugular vein. The aortic clamping was performed with an endoaortic balloon in 106 patients (central kit in 50 cases and peripheral kit in 56) and with a transthoracic clamp in the remaining 60 patients (Portaclamp system in 37 cases and Chitwood clamp in 23). ASDs were corrected by primary suture (with 3 to 6 separate stitches) in 147 patients $(88.5 \%)$ and with a PTFE patch in 19 patients $(11.5 \%)$. All patients had transesophageal echocardiography before weaning from $\mathrm{CPB}$, and no residual ASD was detected. There was no intraoperative mortality and no major complication. We had only 2 cases of endoaortic balloon rupture, which happened before we gained 
TABLE 1. Preoperative characteristics of population

\begin{tabular}{|c|c|c|c|}
\hline & No. of cases & Mean \pm SD & $\%$ \\
\hline \multicolumn{4}{|l|}{ Symptoms } \\
\hline Transient ischemic attack & 61 & & 37 \\
\hline Migraine & 17 & & 10 \\
\hline Exersional dyspnea (NYHA II-III) & 87 & & 52 \\
\hline Palpitations & 10 & & 60 \\
\hline \multicolumn{4}{|l|}{ Echocardiographic data } \\
\hline Size of defect (mm) & & $20 \pm 9$ & \\
\hline Mean PAPs (mm Hg) & & $36 \pm 13.5$ & \\
\hline $\mathrm{EF}(\%)$ & & $60 \pm 4.5$ & \\
\hline ASA & 48 & & 29 \\
\hline Qp/Qs ratio & & $2.5 \pm 0.9$ & \\
\hline Hypertension & 33 & & 20 \\
\hline Dyslipidemia & 12 & & 7.2 \\
\hline Paroxysmal atrial fibrillation & 10 & & 6 \\
\hline Chronic atrial fibrillation & 2 & & 1.2 \\
\hline Chronic lung disease & 4 & & 2.4 \\
\hline Diabetes mellitus & 3 & & 1.8 \\
\hline Renal insufficiency & 1 & & 0.6 \\
\hline Surgery after transcatheter closure & 2 & & 1.2 \\
\hline
\end{tabular}

$S D$, Standard deviation; $N Y H A$, New York Heart Association; $P A P$, pulmonary artery systolic pressure; $E F$, ejection fraction; $A S A$, atrial septal aneurysm; $Q p / Q$ s ratio, pulmonary-to-systemic blood flow ratio.

much experience, probably caused by endoclamp pressure exceeding the $450 \mathrm{~mm} \mathrm{Hg}$ limit. Intraoperative characteristics of patients are summarized in Table 2.

\section{Postoperative Course and Complications}

Seventy-one percent (118 patients) of the population had a completely uneventful postoperative course. All patients were rapidly weaned from mechanical ventilation (mean ventilation time, $6.2 \pm 6$ hours), and the mean intensive care unit stay was $18.6 \pm 12.4$ hours. Surgical revision for bleeding from the thoracic wall was necessary in 6 cases, and in all these patients, the source was identified and fixed though the original thoracotomy. Postoperative paroxysmal atrial fibrillation occurred in 24 cases, but only in 1 patient was persistent at the time of discharge. One patient, with complete atrioventricular block, needed a pacemaker implantation. There were no hospital deaths in our series, and the mean hospitalization time was $5.8 \pm 3.9$ days. Transthoracic echocardiography before discharge revealed successful repair, with no residual shunt, in all patients. Other postoperative data are presented in Table 3.

\section{Follow-up and Late Mortality}

Follow-up was obtained in $100 \%$ of patients, and the mean follow-up time was $51 \pm 33$ months. Four patients $(2.4 \%)$ died late during follow-up. There were 2 deaths due to Ewing's sarcoma and 1 due to a pulmonary embolism occurring 10 years after ASD closure. The cause of death was unknown for 1 patient. All patients returned to a normal life and resumed their previous activity. Improvement in symptoms (decrease in NYHA class or improvement in exercise tolerance if preoperative NYHA class was I) occurred in 131 patients $(78 \%)$. Deterioration in functional class occurred only in 3 patients $(1.8 \%)$, and in the remaining 28 cases (all in NYHA class I preoperatively), there was no difference in exercise tolerance after ASD closure. Patients rated the final cosmetic result of surgery (Figure 3): $98.2 \%$ were extremely satisfied and the $1.8 \%$ were satisfied. Reoperation was not required during the follow-up period.
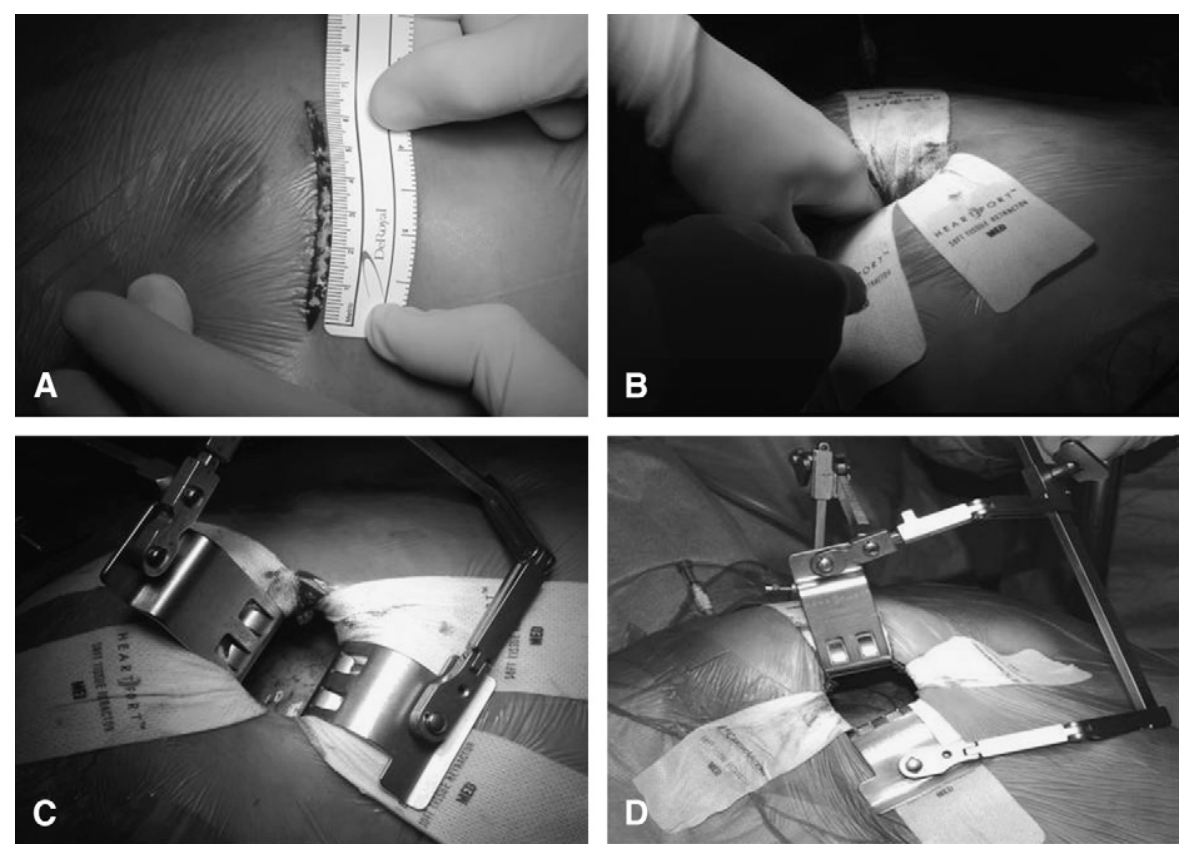

FIGURE 1. A, Skin incision; B, "soft-tissue" retractor; C, Heartport rib retractor; D, excellent exposure of the operative field. 

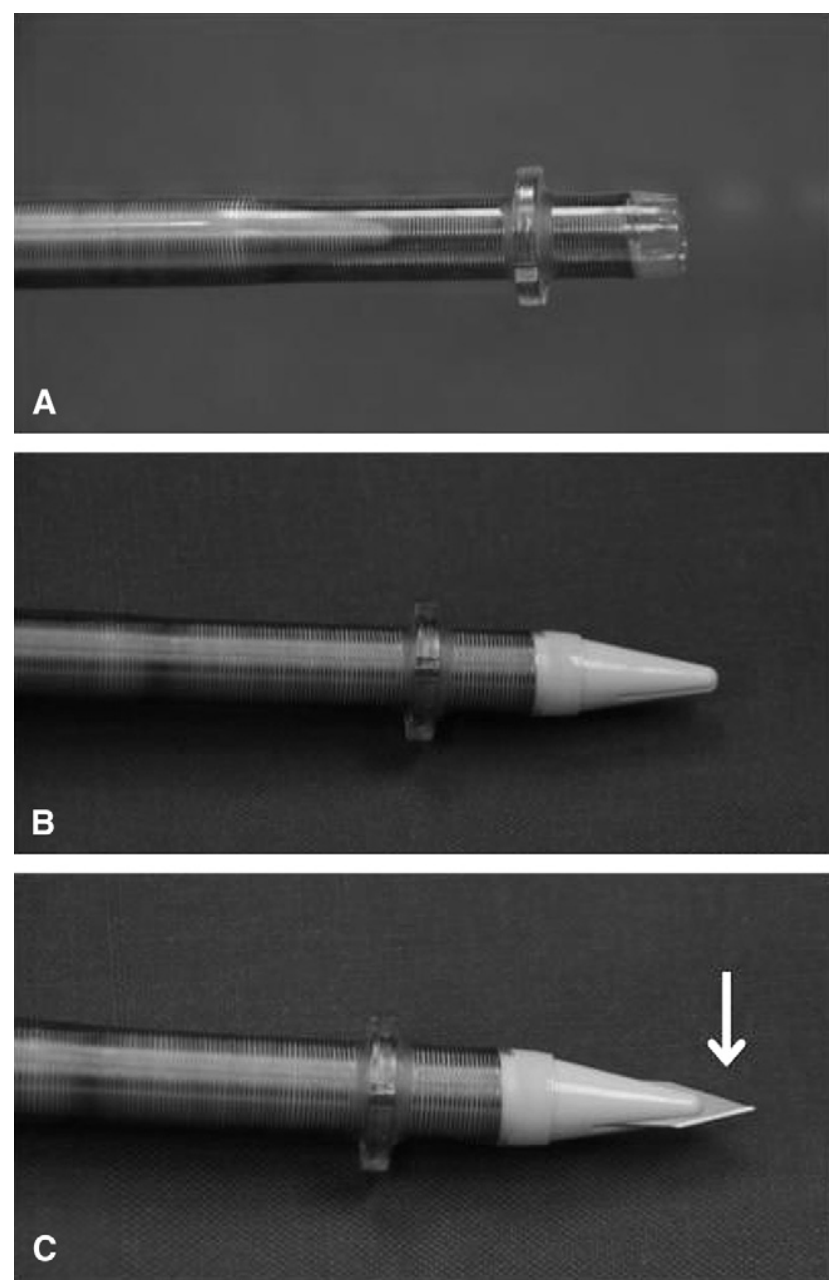

FIGURE 2. A, Central aortic cannula; B, central aortic cannula with the "AutoIncisor" device; $\mathrm{C}$, the retractile blade of the device (arrow).

No surgical wound problems were observed, and the small incision was fairly well tolerated by all patients. Postoperative echocardiography was collected for $86 \%$ of patients and revealed a trivial residual shunt only in 2 cases. All patients, except 1 with known carotid artery disease, stopped antiaggregation therapy after surgery, and no new cerebral episodes were reported during the follow-up period. Five patients $(3 \%)$ developed paroxysmal atrial fibrillation postoperatively, and another $3(1.8 \%)$ needed a pacemaker implant due to severe bradycardia. Two patients $(1.2 \%)$ developed pericarditis that was medically treated.

\section{DISCUSSION}

Surgical closure of ASDs with median sternotomy has been considered the standard approach for almost 50 years. This is a low-risk surgical method, with no operative mortality, very low morbidity, and excellent long-term outcome. ${ }^{9,10}$ Why, then, should we diverge from a highbenefit and low-risk procedure? Obviously because this ap-
TABLE 2. Intraoperative characteristics of patients

\begin{tabular}{|c|c|c|c|}
\hline & $\begin{array}{c}\text { No. of } \\
\text { patients }\end{array}$ & Mean \pm SD & $\%$ \\
\hline \multicolumn{4}{|l|}{ Arterial cannulation } \\
\hline Femoral artery & 78 & & 47 \\
\hline Ascending aorta & 88 & & 53 \\
\hline \multicolumn{4}{|l|}{ Type of clamping } \\
\hline Endoaortic balloon & 106 & & 64 \\
\hline Central kit & 50 & & 30 \\
\hline Peripheral kit & 56 & & 34 \\
\hline Transthoracically & 60 & & 36 \\
\hline Portaclamp system & 37 & & 22 \\
\hline Chitwood clamp & 23 & & 14 \\
\hline \multicolumn{4}{|l|}{ ASD closure technique } \\
\hline Primary suture & 147 & & 88.5 \\
\hline PTFE patch & 19 & & 11.5 \\
\hline CPB time (min) & & $64.9 \pm 34.5$ & \\
\hline Aortic cross clamp time (min) & & $38.4 \pm 22.2$ & \\
\hline Associated procedures & 19 & & 11.5 \\
\hline PARPVD repair & 6 & & 3.6 \\
\hline Mitral valvuloplasy & 2 & & 1.2 \\
\hline Mitral valve cleft closure & 3 & & 1.8 \\
\hline Tricuspid De-Vega valvuloplasty & 4 & & 2.4 \\
\hline $\begin{array}{l}\text { Right-sided maze procedure } \\
\text { with radiofrequency }\end{array}$ & 2 & & 1.2 \\
\hline Ventricular septal defect closure & 1 & & 0.6 \\
\hline Iatrogenic AR-RA fistula closure & 1 & & 0.6 \\
\hline $\begin{array}{l}\text { Lowest esophageal } \\
\text { temperature }\left({ }^{\circ} \mathrm{C}\right)\end{array}$ & & $33.2 \pm 2.3$ & \\
\hline Skin incision $(\mathrm{cm})$ & & $5.5 \pm 1$ & \\
\hline Endoaortic balloon rupture & 2 & & 1.2 \\
\hline Death in operating room & 0 & & 0 \\
\hline
\end{tabular}

$S D$, Standard deviation; $A S D$, atrial septal defect; $P T F E$, polytetrafluoroethylene; $C P B$, cardiopulmonary bypass; $P A R P V D$, partial anomalous right pulmonary venous drainage; $A R-R A$, aortic root-to-right atrium.

proach entails operative trauma and large surgical wounds, which may cause psychologic distress and negative influence on the quality of life of young and often female patients, who are usual candidates for ASD repair. In this "incisionless era," a 20-cm skin incision is probably no longer considered acceptable to repair a 2-cm septal defect, but cosmetic results must be balanced against the safety of the procedure. In the past several years, we have seen the development of various minimally invasive approaches as a result of technical innovations in surgical instruments, CPB technology, and transthoracic and endovascular clamping. ${ }^{5-7}$ At our institution, the port-access surgery, via a right minithoracotomy in the fourth intercostal space, has become the standard approach not only for ASDs closure but also in cases of mitral valve surgery, tricuspid valve surgery, atrial myxoma, surgical treatment of atrial fibrillation, and ventricular septal defects (membranous or inlet types). After 10 years' experience, with more than 1200 patients operated on with this method, ASD repair is no longer considered a challenging and time-consuming procedure at our center. ${ }^{11}$ 
TABLE 3. Postoperative course and complications

\begin{tabular}{lccr}
\hline & No. of patients & Mean \pm SD & $\%$ \\
\hline ICU stay (h) & $18.6 \pm 12.4$ & \\
Ventilation time (h) & $6.2 \pm 6$ & \\
Hospitalization total (d) & $5.8 \pm 3.9$ & \\
24-h drainage (mL) & $310 \pm 215$ & \\
Drainage (d) & $2.1 \pm 0.8$ & \\
Paroxysmal atrial fibrillation & 24 & & 14.4 \\
Persistent atrial fibrillation & 1 & & 0.6 \\
Surgical revision for bleeding & 6 & & 3.6 \\
Hyperthermia & 7 & & 4.2 \\
Pacemaker implantation & 1 & & 0.6 \\
Pneumothorax & 3 & & 1.8 \\
Transfusions & 9 & & 5.4 \\
Inguinal lymphorrhea & 1 & & 0.6 \\
\hline
\end{tabular}

$S D$, Standard deviation; $I C U$, intensive care unit.

In our experience, the average $\mathrm{CPB}$ and aortic crossclamping times for ASDs closure were $64.9 \pm 34.5$ and $38.4 \pm$ 22.2 minutes, respectively. These results are comparable with those reported in other series, whether lower partial sternotomy ${ }^{12}$ right thoracotomy ${ }^{5,13}$ or varied minimally invasive surgical approaches ${ }^{7}$ were performed. The latest step in the surgical evolution of ASD repair is robotic technology. ${ }^{6,14,15}$ By avoiding thoracotomy incisions and rib spreading, this procedure results in minimal pain and postoperative recovery time, overall patient satisfaction, and excellent cosmesis, but it has some certain limitations. First, it is technically challenging and time-consuming, with CPB and aortic crossclamping times almost double compared with the reported experiences with port-access approach. ${ }^{7,13}$ Moreover, in our study, surgery was performed with shorter operative times, although procedure duration is longer in case of PTFE patch closure (11.5\% in our series) and associated procedures (11.5\% in our series). Second, costs for robotic surgery are still very high, and the hospital length of stay of patients (from 4 to 9.5 days) $)^{6,14,15}$ is not lower if compared with our port-access experience (5.8 days) and that of others (from 3.98 to 8.2 days). ${ }^{5,7,13}$ Finally, the absence of tactile feedback with robotic assistance could turn a simple suture into a technically difficult procedure that entails potential risk of ASD recurrence. ${ }^{6,7}$ In our study, complete closure of ASD was confirmed in all patients with intraoperative transesophageal echocardiography, and no significant residual shunts were identified after a mean follow-up time of 51 months.

Surgical strategy and good exposure were the keys to the success of this minimally invasive approach. By using both a soft tissue retractor and a rib retractor, we always obtained an excellent exposure of the operative field. Both arterial and venous cannulations were kept out of the operative field. The fact that both femoral and jugular vein were cannulated, encircled by vascular loops and snared, allowed perfect venous drainage in almost all cases. Furthermore, the possibility of

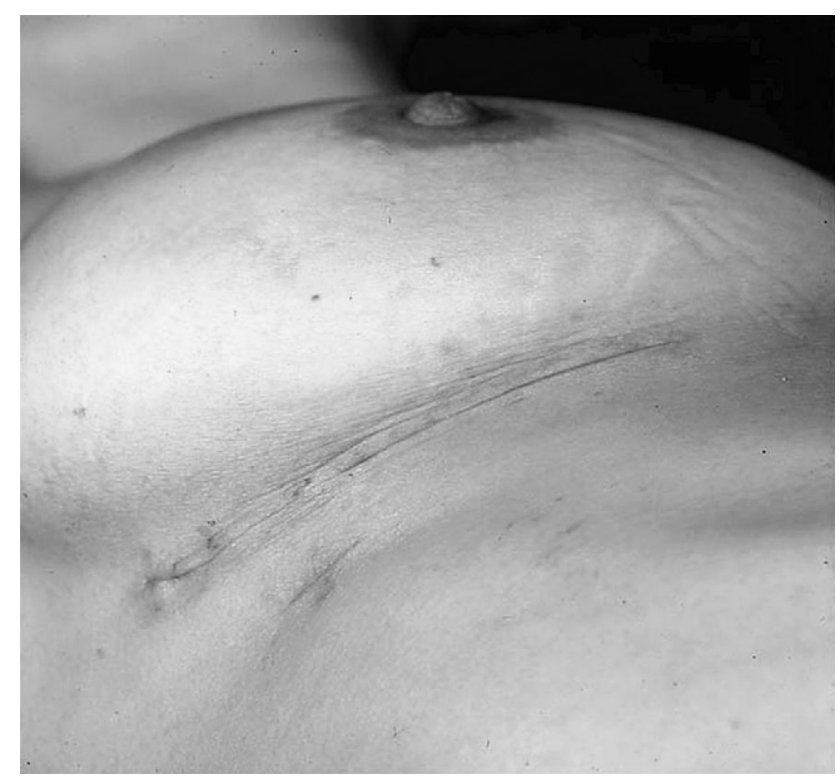

FIGURE 3. Excellent cosmetic result of surgery.

performing a central arterial cannulation makes this technique suitable also for patients with peripheral vascular disease involving the iliac or femoral vessels.

Another advantage of this type of surgery, compared with standard sternotomy, is the fact that patients needing reoperation can be operated on using a different surgical approach. Therefore, reentry problems are avoided as a wide dissection is not necessary, a peripheral arterial cannulation can be performed, and the aortic clamping can be obtained with an EndoClamp. On the other hand, this minimally invasive approach could create fewer adhesions in the long term, considering the fact that intrathoracic dissection and trauma are limited. This could be crucial in the case of future reoperation, especially in a population of relatively younger people.

After using different perfusion (central and peripheral cannulation) and aortic clamping (endoclamp or transthoracic clamp) techniques, we report here our preferred approach for a specific clinical context: (1) peripheral vascular disease or aortic atheroma: central cannulation; (2) patients needing reoperation: peripheral cannulation; (3) aortic diameter $>35$ $\mathrm{mm}$ : central cannulation with transthoracic clamping (risk of incomplete aortic endoclamping); (4) aortic diameter $<20$ $\mathrm{mm}$ : peripheral cannulation (risk of injury to the posterior wall of the aorta using the AutoIncisor device); (5) female patients: peripheral cannulation (preferred; unaesthetic scar over the right breast due to the transthoracic clamp in case of central cannulation); (6) obesity and/or diabetes mellitus: central cannulation (presumed augmented risk of inguinal lymphorrhea or infection in the femoral groove). In the case of peripheral cannulation, aortic crossclamping is obtained with an endoclamp, and in the case of central cannulation, the Chitwood clamp is actually our preferred (lower cost if compared with the Portaclamp). 
Concerning the safety of this technique, as previously described, ${ }^{16}$ the port-access approach is a low-risk and highly successful procedure: in our series all patients survived the operation, and no major surgical complication was experienced. These achievements may be related to our well-established experience in minimally invasive surgery and to technical improvements in $\mathrm{CPB}$, surgical instruments, and clamping devices. We did not encounter any thromboembolic event or complication related to peripheral cannulation, such as iliofemoral or aortic retrograde dissections. These theoretical disadvantages of port-access approach could occur especially in the case of diffuse atherosclerosis, which is an uncommon situation in a relatively young population such as the one considered in our study. However, if necessary, a central arterial cannulation, associated with transthoracic clamping, can be employed to prevent these risks in patients with peripheral vascular disease or aortic atheroma. Another reported drawback of the port-access approach is phrenic nerve damage. In this ASDs cohort, we did not experience any injury to the nerve, but it was a complication that was noted at the beginning of our general experience with port-access surgery. We believe that it could be easily prevented by a careful definition of the course of the phrenic and by opening the pericardium $2 \mathrm{~cm}$ away from it, avoiding the use of topical cooling. Surgical revision for bleeding from the thoracic wall was necessary in 6 patients, but this was another complication encountered only at the beginning of our experience. The main cause of bleeding was the injury to an intercostal artery, an accident that can easily occur considering the peculiar characteristics of this type of surgery (transthoracic clamping, central percutaneous arterial cannulation, pericardial stay sutures passed out of the chest). Concerning postoperative pain, Walther and colleagues ${ }^{17}$ reported higher pain levels during the first 2 postoperative days in patients operated on through a minithoracotomy. With this approach, in fact, the rib-spreading effect can produce intercostal nerve damage and consequent increase of postoperative pain. In our study, we did not perform pain scoring, considering that pain perception is difficult to standardize and that individual thresholds can vary according to differences in sex, age, race, and socioeconomic status. However, the use of soft tissue retractors during operation and antalgic therapy postoperatively can help to control or minimize pain.

New-onset paroxysmal atrial fibrillation was the most common postoperative complication observed in our series $(14.4 \%)$. Nevertheless, in only 1 patient $(0.6 \%)$ was this persistent at the time of discharge. Older age at surgery was the only predictor of paroxysmal atrial fibrillation $(P<.0001$; odds ratio, $1.08 ; 95 \%$ confidence interval, 1.04-1.12) between all pre- and intraoperative variables considered in our univariate analysis. Possible mechanisms involved in these patients are long-standing right atrial dilatation, atrial fibrosis, and pulmonary hypertension, probably amplified by the effect of surgical scars. ${ }^{18,19}$
Finally, regarding a comparison of this minimally invasive technique with interventional approaches involving different occluder systems, several points should be considered. First, device closure is impracticable or unsuitable in the following cases: (1) defects too large for occlusion; (2) multiple defects; (3) coronary sinus defects; (4) defects associated with atrial septal aneurysm, mitral valve cleft, or partial abnormal pulmonary vein connection; (5) distance of $<5$ $\mathrm{mm}$ from the margins of the ASD to the pulmonary veins, atrioventricular valves, coronary sinus, or superior vena cava; (6) presence of associated cardiac pathologies requiring surgical repair. The $20.5 \%$ of the ASDs in our series were complex $(9 \%)$ or associated with other cardiac anomalies $(11.5 \%)$; therefore, this cohort demonstrates that all types of defect can be safely approached and corrected by port-access surgery. Second, interventional techniques for ASDs closure are associated with a $95 \%$ early efficacy, ${ }^{3,4}$ and successful closure is achieved in $100 \%$ of patients treated by surgery. ${ }^{3,7,16,20}$ Even if residual shunts after device closure are often not hemodynemically significant and most will close spontaneously within 1 year, ${ }^{3}$ it remains true that, on the other hand, surgical repair ensures an effective repair in all patients (including those with complex defects) and, most importantly, with excellent long-term outcome. ${ }^{10}$ The limited follow-up of most reported series of transcatheter closure and the lack of randomized studies comparing interventional and surgical therapies make it imprudent to conclude that interventional techniques are comparable or even preferable to the surgical approach, regardless of patient selection. ${ }^{21,22}$ Third, despite the technical improvements in transcatheter occluder devices, several major complications are still documented: (1) device dislocation and consequent peripheral embolization; (2) significant residual defect requiring surgical reoperation; (3) neurologic events during or after procedure; (4) early cardiac perforation with tamponade; (5) injuries to intracardiac structures; (6) obstruction to systemic and pulmonary venous drainage; (7) endocarditis; (8) postprocedural thromboembolic risk; (9) late erosion or perforation of the atrial wall and the aortic root. ${ }^{3,20,21,23,24}$ Although uncommon (occurring in around $1 \%-2 \%$ of patients), these complications may lead to extremely dangerous consequences (cardiac failure, death, or stroke) and a poor outcome in patients with a relatively benign defect. Walther and colleagues ${ }^{20}$ reported a series of 15 patients requiring secondary surgical therapy after interventional occluder placement; the functional outcome of this population was excellent, even in the presence of severe complications. In our study, we had 2 cases of incomplete occlusion of ASD after transcatheter closure, associated, in 1 patient, with an iatrogenic aortic root-to-right atrium fistula (as previously reported in detail). ${ }^{23}$ In both cases, the device was removed, the correction was easily performed, and the postoperative course was uneventful, ensuring a satisfactory clinical outcome. Briefly, 
percutaneous closure of ASD has gained widespread popularity among patients and cardiologists, but, as serious complications may occur using this technique, in our opinion, a surgical standby should be preferable. Finally, device closure of ASD is shown to be associated with shorter hospital stay, better quality of life, and earlier return to normal activity compared with the surgical approach. This can be true if we consider only the conventional sternotomy but, in the current era of minimally invasive surgery, a comparison must be made to the port-access approach. In fact, a less invasive surgical technique ensures a low-risk and highly successful procedure, with low morbidity, a short hospital stay, early mobilization and return to work, good cosmesis, and high patient satisfaction, and, what is more, with an excellent long-term result.

\section{CONCLUSIONS}

From our experience, port-access minimally invasive surgery for ASDs is a safe, minimally invasive, reproducible, and cosmetic operation that guarantees an outstanding clinical result and a durable anatomic correction. These achievements are reached even in the presence of complex defects or associated cardiac pathologies. Percutaneous techniques will probably remain in the treatment of selected ASDs but the port-access approach should now be considered the standard treatment option. Only a real perspective randomized trial, comparing transcatheter and minimally invasive surgical closure, can provide an incontrovertible answer.

\section{References}

1. Konstantinides S, Geibel A, Olschewski M, Gornandt L, Roskamm H, Spillner G, et al. A comparison of surgical and medical therapy for atrial septal defect in adults. N Engl J Med. 1995;33:469-73.

2. King TD, Thompson SL, Steiner C, Mills NL. Secundum atrial septal defect. Nonoperative closure during cardiac catheterization. JAMA. 1976;235:2506-9.

3. Du ZD, Hijazi ZM, Kleinman CS, Silverman NH, Larntz K. Comparison between transcatheter and surgical closure of secundum atrial septal defect in children and adults. J Am Coll Cardiol. 2002;39:1836-44.

4. Webb G, Gatzoulis MA. Atrial septal defects in the adult: recent progress and overview. Circulation. 2006;114:1645-53.

5. Ryan WH, Cheirif J, Dewey TM, Prince SL, Mack MJ. Safety and efficacy of minimally invasive atrial septal defect closure. Ann Thorac Surg. 2003;75: 1532-4.

6. Argenziano M, Oz MC, Kohmoto T, Morgan J, Dimitui J, Mongero L, et al. Totally endoscopic atrial septal defect repair with robotic assistance. Circulation. 2003;108: II-191-4.
7. Ak K, Aybek T, Wimmer-Greinecker G, Özaslan F, Bakhtiary F, Moritz A, Dogan S. Evolution of surgical techniques for atrial septal defect repair in adults: a 10-year single-institution experience. J Thorac Cardiovasc Surg. 2007;134: 757-64.

8. Hongxin L, Wenbin G, Lijun S, Zhengjun W, Hao L, Chengwei Z, et al. Intraoperative device closure of secundum atrial septal defect with a right anterior minithoracotomy in 100 patients. J Thorac Cardiovasc Surg. 2007;134:946-51.

9. Horvath KA, Burke RP, Collins JJ Jr, Cohn LH. Surgical treatment of adult atrial septal defect: early and long-term results. J Am Coll Cardiol. 1992;20: 1156-9.

10. Murphy JG, Gersh BJ, McGoon MD, Mair DD, Porter CJ, Ilstrup DM, et al. Long term outcome after surgical repair of isolated atrial septal defect. Follow-up at 27 to 32 years. $N$ Engl J Med. 1990;323:1645-50.

11. Formigari R, Di Donato RM, Mazzera E, Carotti A, Rinelli G, Parisi F, et al. Minimally invasive or interventional repair of atrial septal defects in children: experience in 171 cases and comparison with conventional strategies. J Am Coll Cardiol. 2001;37:1707-12.

12. Black MD, Freedom RM. Minimally invasive repair of atrial septal defects. Ann Thorac Surg. 1998;65:765-7.

13. Mishaly D, Ghosh P, Preisman S. Minimally invasive congenital cardiac surgery through right anterior minithoracotomy approach. Ann Thorac Surg. 2008;85: 831-5.

14. Wimmer-Greinecker G, Dogan S, Aybek T, Khan MF, Mierdl S, Byhahn C Moritz A. Totally endoscopic atrial septal repair in adults with computerenhanced telemanipulation. J Thorac Cardiovasc Surg. 2003;126:465-8.

15. Bonaros N, Schachner T, Oehlinger A, Ruetzler E, Kolbitsch C, Dichtl W, et al Robotically assisted totally endoscopic atrial septal defect repair: insights from operative times, learning curves, and clinical outcome. Ann Thorac Surg. 2006; 82:687-93.

16. Spreafico P, Rinaldi M, Alloni A, Perrotta S, Grasselli F, Viganò M. Minimally invasive closure of patent foramen ovale through port-access surgery. Neurol Sci. 2003;24:S20-2.

17. Walther T, Falk V, Metz S, Diegeler A, Battellini R, Autschbach R, Mohr FW Pain and quality of life after minimally invasive versus conventional cardiac surgery. Ann Thorac Surg. 1999;67:1643-7.

18. Gatzoulis MA, Hechter S, Webb GD, Williams WG. Surgery for partial atrioventricular septal defect in the adult. Ann Thorac Surg. 1999;67:504-10.

19. Kobayashi J, Yamamoto F, Nakano K, Sasako Y, Kitamura S, Kosakai Y. Maze procedure for atrial fibrillation associated with atrial septal defect. Circulation. 1998;98: II-399-402.

20. Walther T, Binner C, Rastan A, Dähnert I, Doll N, Falk V, et al. Surgical atria septal defect closure after interventional occluder placement: incidence and outcome. J Thorac Cardiovasc Surg. 2007;134:731-7.

21. Berger F, Vogel M, Alexi-Meskishvili V, Lange PE. Comparison of results and complications of surgical and Amplatzer device closure of atrial septal defects. J Thorac Cardiovasc Surg. 1999;118:674-8.

22. Moritz A, Özaslan F, Dogan S, Abdel-Rahman U, Aybek T, WimmerGreinecker G. Closure of atrial and ventricular septal defects should be performed by the surgeon. J Intervent Cardiol. 2005;18:523-7.

23. Raffa G, Pellegrini C, Lentini S, Perrotta S, Tancredi F, Gaeta R, Viganò M. Minimally invasive video-assisted surgery for iatrogenic aortic root-to-right atrium fistula after incomplete percutaneous occlusion of patent foramen ovale: case report and review of the literature. J Card Surg. 2008;23:75-8.

24. Palma G, Rosapepe F, Vicchio M, Russolillo V, Cioffi S, Vosa C. Late perforation of right atrium and aortic root after percutaneous closure of patent foramen ovale J Thorac Cardiovasc Surg. 2007;134:1054-5. 